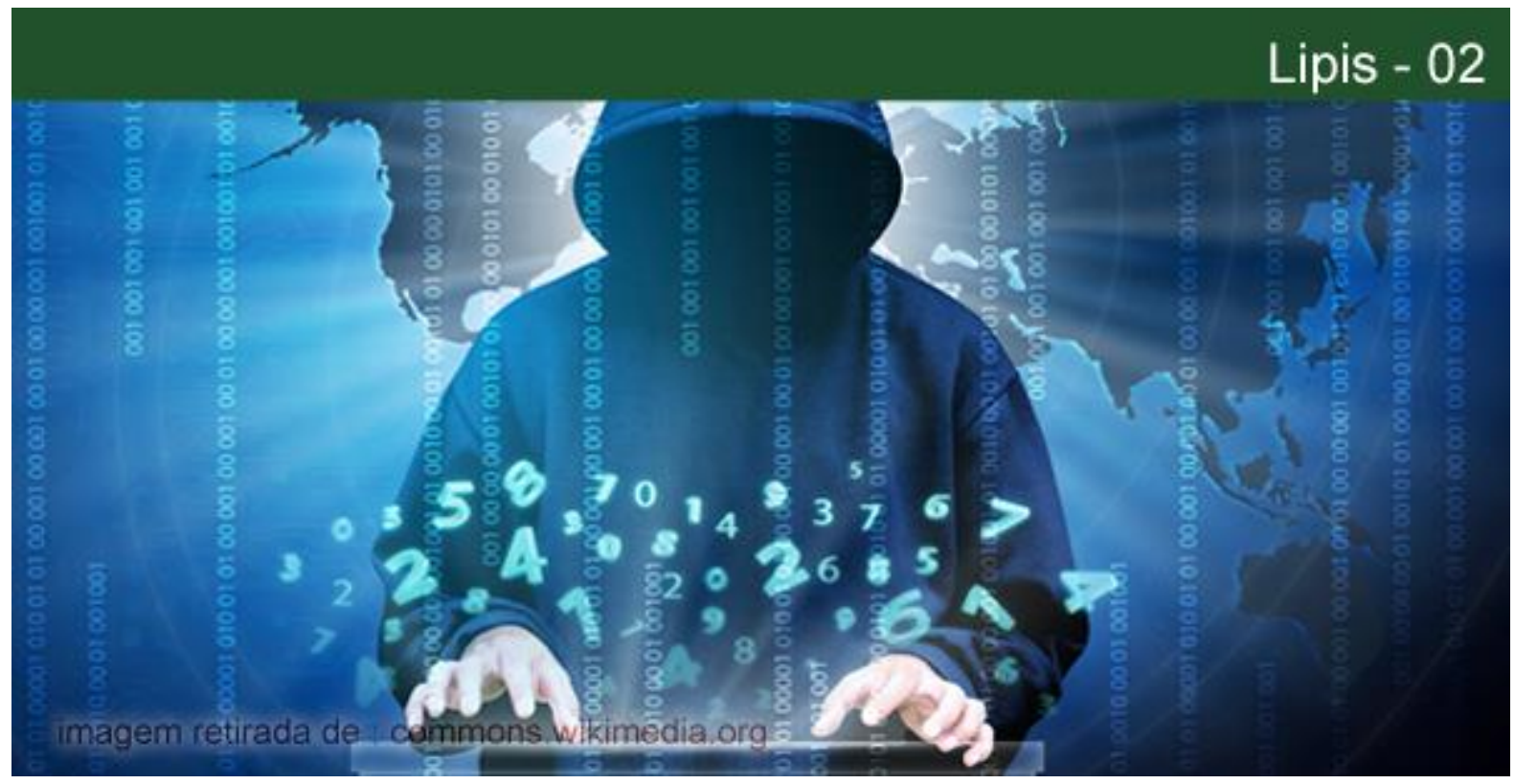

\title{
A INTERNET COMO UMA POSSIBILIDADE DE EMPODERAMENTO DAS CLASSES POPULARES URBANAS NO BRASIL
}

\section{Paula Melgaço}

Doutoranda em Psicologia Clínica pela Pontifícia Universidade Católica (PUC-Rio). Pesquisadora e cocoordenadora do Núcleo de tecnologia e adolescência do Laboratório Interdisciplinar de Pesquisa e Intervenção Social (LIPIS/PUC-Rio). E-mail: paulamelgaco.psi@gmail.com.

\section{Bruna Madureira}

Doutoranda em Psicologia Clínica pela Pontifícia Universidade Católica (PUC-Rio). Pesquisadora do Laboratório Interdisciplinar de Pesquisa e Intervenção Social (LIPIS/PUC-Rio). E-mail: bruna.madureira@hotmail.fr.

Resumo: O presente trabalho tem como objetivo pensar a internet e seus recursos, em especial as redes sociais, como um cenário de empoderamento das classes populares urbanas brasileiras que encontram nesse espaço a oportunidade de expressar suas opiniões, socializar com amigos e familiares e descobrir novos horizontes e conjunturas. Trata-se de um lugar longe do olhar opressor e estigmatizado de diversas instâncias sociais e do Estado, para além de seus cotidianos marcados pela alta violência e desigualdade. Portanto, a internet parece oferecer a esses indivíduos um meio em que se sentem seguros, ainda que haja certa resistência da elite em compartilharem os mesmos espaços virtuais, para expor a realidade em que vivem e refletir sobre ela, se divertir e fortalecer os laços interpessoais.

Palavras-chave: Internet. Empoderamento. Classes populares brasileiras.

\section{THE INTERNET AS A POSSIBILITY OF EMPOWERMENT OF THE URBAN POPULAR CLASSES IN BRAZIL}

Abstract: The present work aims to think about the Internet and its resources, especially social networks, as a scenario of empowerment of the Brazilian urban popular classes who find in this space the opportunity to express their opinions, socialize with friends and family and discover new horizons and conjunctures. It's a place far from the oppressive and stigmatized look of various social and state instances, that goes beyond their daily lives marked by violence and inequality. Therefore, the Internet seems to offer for these individuals a safe environment, although there is some resistance from the elite to share the same virtual spaces with them, to

\section{POLÊM!CA $\mid$ LABORE (}

Polêmica - Revista Eletrônica da Uerj - Rua São Francisco Xavier, 524, $1^{\circ}$ andar bloco D, sl.1001 • Tels.: +55 21 2334-4088/4087 • http://www.e-publicacoes.uerj.br/index.php/polemica/index http://www.labore.uerj.br • laboreuerj@yahoo.com.br 
expose the reality in which they live and to reflect about it, to have fun and to strengthen interpersonal relationships.

Keywords: Internet. Empowerment. Brazilian popular classes.

The Life Games [LAN house] is right next to my house and I can use their Wi-Fi connection... I put my hand in my pocket and just to know that it is in there [Facebook], I feel safer. With it I can get out of this crazy reality anytime Iwant. I can cry, scream about my pain because I know that someone will be here, online, listening to me... I can for a moment be myself. [...] It is like Face is my best friend. (Relato de uma das entrevistadas do pesquisador David Nemer, 2015, p.185).

\section{Introdução}

O surgimento da internet na década de 60 e a sua exponencial popularização têm se constituído como um dos mais significativos fenômenos culturais da atualidade. O impacto da criação desse aparato tecnológico pode ser facilmente observado em diversas áreas, sobretudo no comportamento humano. É interessante notar como que, no decorrer dos anos, a internet tornou-se um espaço particularmente importante para as relações humanas. A vida social ganhou novos contornos a partir da invenção dessa nova ferramenta que tem a capacidade de maximizar o contato entre as pessoas, aproximar conhecidos ou desconhecidos e reduzir distâncias de modo a transformar completamente a experiência espaço-temporal. Em tempos de acelerados avanços tecnológicos, interações antes inimagináveis, hoje, ocorrem de maneira muito simples e instantânea.

Algumas das implicações que a internet trouxe para o relacionamento humano foram as transformações subjetivas geradas a partir do uso desta nova ferramenta como, por exemplo, o surgimento de comunidades virtuais (blogs, vlogs e redes sociais). Ao adentrar no mundo online, o sujeito modifica o seu jeito de ser e estar no mundo, que passa a ser mediado pela rede tecnológica. Assim sendo, a relação mediada pela tecnologia é incorporada no dia a dia do sujeito contemporâneo que já não concebe a possibilidade de passar um dia sequer desconectado. Um dos resultados mais notáveis é que a sociabilidade passa a ser dinamizada pelas relações em rede, que carrega a conexão ilimitada e a instantaneidade como premissas básicas.

A internet revela-se por meio de um palco repleto de informação e comunicação, tornando-se uma matriz funcional de laços múltiplos. A vida comunitária ganha força e toma conta do espaço tecnológico, caracterizando-se enquanto um ambiente de convivência que passa a ser frequentado regularmente e no qual as pessoas desenvolvem relações importantes

\section{POLÊM!CA $\mid$ LABORE}


não apenas para seu desenvolvimento em termos sociais, mas para a sua constituição subjetiva (ARAUJO, 2005). Destarte, a internet trouxe diversas mudanças para a sociedade, como a transformação dos costumes, das formas de se relacionar e, acima de tudo, no que tange aos processos de subjetivação e socialização.

Castells (2006) assevera que a internet tornou-se o meio mais poderoso de comunicação na atualidade ao possibilitar a interligação de pontos distantes do planeta a um custo menor e a uma velocidade maior. Levy (1999) corrobora a teoria de Castells ao afirmar que "as tecnologias digitais surgiram como uma infraestrutura do ciberespaço, um novo espaço de comunicação, sociabilidade, organização e transação” (p. 32). Se a internet é, em essência, um meio de comunicação, ela pode ser usada para diversos fins: relacionamento, negócio, pesquisa, criação, etc. Ao apresentar diversas opções (e-mails, vídeos, mensagens instantâneas, blogs, salas de bate-papo e redes sociais), a internet abre as portas de um mundo completamente inédito para o usuário que se vê ansioso para explorar cada utensílio e ambiente que lhe são apresentados.

Ao explorar a rede social, o sujeito constrói possibilidades de interação. Ao se constituir enquanto espaço público, a rede fornece diversas oportunidades que podem se transformar em tramas sociais. Segundo Dias e De Lataille (2004), a popularização desta tecnologia se deu sobretudo em virtude do incremento das relações interpessoais, isto é, da facilidade de criar novos laços sociais. Sendo assim, a rede social não se constitui apenas enquanto lugar de formação e circulação de conteúdos simbólicos, mas possui um poder transformador de restruturação do espaço de interação, de modo a propiciar novas configuração e produção de sentidos.

Sem dúvida, a troca de informações e a exposição de si nos posts compartilhados suscitam transformações na vida dos usuários. Os blogs, assim como as redes sociais (Facebook, Instagram e Snapchat), anunciam-se como espécies de diários eletrônicos íntimos abertos ao público. O presente artigo, no entanto, não tem o objetivo de explorar a relação entre público e privado, imagens compartilhadas enquanto diário de tela ou a internet enquanto um espaço de exposição narcísica. Embora esses também sejam temas relevantes para pesquisa, este artigo busca investigar os usos que as classes populares urbanas brasileiras fazem da internet, focando naqueles que fomentam o empoderamento e a autonomia.

\section{POLÊM!CA $\mid$ LABORE}




\section{O uso da internet pelas classes populares urbanas no Brasil}

Se sabemos que nos países desenvolvidos como os Estados Unidos, berço da Internet, esta ampliou seu escopo de usuários nas diversas camadas da população, como se deu este processo na realidade brasileira? Seria a internet somente mais uma expressão da desigualdade social do país?

De acordo com a pesquisa "Tecnologia de Informação e Comunicação DomicíliosTIC Domicílios Brasil" (2015), dentre os indivíduos inseridos nas classes D/E e C, respectivamente, $16 \%$ e $56 \%$ tem acesso ao mundo virtual. Além da falta de recursos disponibilizados pelo governo para o setor, os principais motivos alegados pelos indivíduos que não tem acesso à internet são: falta de computador em domicílio, falta de necessidade e interesse dos moradores, alto custo para manter uma conexão de banda larga em casa e a falta de conhecimento sobre usar os recursos tecnológicos (CETIC, 2015).

Em relação àqueles que têm acesso à internet: $81 \%$ dos usuários das classes D/E e $84 \%$ da classe C enviaram mensagens via what's app, chat do Facebook ou Skype; $68 \%$ das classes D/E e $76 \%$ da classe C fizeram uso de redes sociais como, Facebook, Instagram e Snapchat (CETIC, 2015) Tais estatísticas revelam uma prevalência das redes sociais nas preferências dos indivíduos das classes populares que têm a possibilidade de ficar conectados ao mundo virtual. A seguir, será demonstrado que os números não estão afastados do contexto social, pois não é ao acaso que esses recursos são os mais utilizados por aqueles que usufruem dessa infraestrutura.

Ao se analisar os dados acima, impressão inicial pode ser a de que o uso da internet pelas classes B, C e D no Brasil limita-se a uma interpretação cujo foco seria a desigualdade social e problemáticas relacionadas à inclusão digital. Embora esses sejam assuntos de incontestável importância, o foco do presente trabalho é retratar conjunturas que lutam contra a exclusão social, a invisibilidade e a violência por meio do instrumental disponível na internet.

O que se observa é que a camada social se apropria da tecnologia de uma maneira peculiar, intrinsecamente relacionada ao contexto onde estão inseridas. No cenário das classes populares, por exemplo, a utilização da internet, e particularmente das redes sociais, possibilita uma nova forma de se relacionar dentro de um contexto que é particularmente

\section{POLÊM!CA $\mid$ LABORE}


regido pela violência, hostilidade e brutalidade. Por conseguinte, alvitra-se a hipótese de que o uso das redes sociais para esses sujeitos constitui-se enquanto forma de empoderamento.

Tal suposição fica patente, por exemplo, no uso de ferramentas virtuais, tais como YouTube ou blogs, que inauguram uma nova base de conhecimento. É interesse notar o quanto o impacto de alguns sites (que oferecem cursos como costura, culinária, decoração, entre outros) no processo de aprendizado de alguns indivíduos, engendrando, inclusive, mudanças em suas vidas, sobretudo nos campos educacionais e profissionais. Desse modo, a internet ganha novos contornos ao ser apropriada de uma forma diversa pelos sujeitos de baixa renda e é inegável o impacto positivo que essas ferramentas têm em suas vidas.

As redes sociais provocam igualmente uma modificação na vida dessas pessoas. Uma das questões básicas que se coloca em suas vidas é a falta de saneamento básico, bem como o acesso à saúde e à educação. Em relação a esta, é imperativo salientar as altas taxas de analfabetismo funcional nos estratos sociais menos privilegiados da população, devido à péssima qualidade de ensino no Brasil e da dificuldade de inserção desse público nas escolas. Conforme anteriormente descrito, alguns sites são usados como fonte de aquisição de conhecimento sobre temas diversos. Contudo, são as redes sociais que provocam mudanças interessantes em casos de alguns analfabetos funcionais. Ao desejarem fazer parte desse mundo, buscam não apenas uma inserção online, como também a construção de estratégias para usufruírem de seus recursos cotidianamente, por meio do envio e recepção de mensagens e/ou compartilhamento de fotos, vídeos e textos. Essa tarefa, supostamente simples, coloca-se como uma árdua atividade para quem não compreender o que lê ou escreve (NEMER; FREEMAN, 2015).

Esse obstáculo, no entanto, não impede que as pessoas façam uso da ferramenta. Novamente, o interessante é notar a apropriação que esse coletivo faz da rede social. Apesar de não compreender formalmente todos recursos disponíveis, ele se apropria dos mesmos para dar os primeiros passos, de modo a aprender a ler e a escrever. Em outros casos, ainda que não se alfabetizem, alguns indivíduos, com o auxílio da comunidade, conseguem usufruir instintivamente da internet lançando mão de outros recursos, em especial da imagem.

Assim sendo, a rede social constitui-se enquanto uma possibilidade de empoderamento, na medida em que permite ao sujeito ganhar conhecimento e,

\section{POLÊM!CA $\mid$ LABORE}


consequentemente, sair da categoria de iletrado. O acesso à informação, ainda que informal e virtual, estimula a produção de conhecimento e o pensamento crítico.

De forma similar aos exemplos apresentados anteriormente, existem inúmeros episódios de empoderamento - apropriação de ferramentas encontradas no mundo virtual que culminam em transformações positivas - a partir da conquista da internet pelo sujeito que passa a navegar no mundo virtual em busca de liberdade e autonomia. Isso fica evidente no momento em que um jovem envia selfies para a mãe ausente em virtude do trabalho, não apenas como uma via de expressão de sentimentos, mas, sobretudo, como uma forma de comunicação. Ademais, a internet possibilita o contato entre amigos e familiares que residem em bairros dominados por distintas facções ou que estejam em áreas de risco ou difícil acesso por falta de transporte público e/ou saneamento. No cenário dominado pela insegurança e violência, a internet se torna o único local seguro para o encontro e manutenção de contato entre entes queridos (NEMER; FREEMAN, 2015).

De maneira mais geral, a violência e o perigo rondam os bairros das classes populares, seja pela presença da polícia ou do tráfego, o que implica em uma falta de liberdade não apenas para transitar nos espaços físicos, como também para expressar opiniões e crenças acerca do que se passa ao seu redor. Nesse contexto de ameaça e risco, o sujeito vê na rede social uma possibilidade de segurança, ainda que limitada, para expressar os seus sentimentos com relação a sua vida e a indignação no que tange à falta de segurança ou acesso à saúde e educação. Por isso, entende-se que a internet ganha novos contornos ao ser apropriada pelas classes mais baixas, que utilizam os instrumentos disponíveis na esfera virtual para mostrar ao mundo o seu contexto de vida e, particularmente, a sua luta diária para se manterem vivos apesar da precariedade e incerteza. Não seria isso, afinal, uma forma de empoderamento?

\section{A internet como uma ferramenta de empoderamento}

Apesar da desigualdade presente na sociedade brasileira no que concerne ao acesso à internet, há muitos usuários que fazem usos de suas ferramentas em seus cotidianos como, por exemplo, Facebook, Youtube e jogos online. Nemer e Freeman (2015) investigaram o uso que moradores de favelas brasileiras fazem das selfies e encontraram resultados bastante interessantes sobre esse tipo de autorretrato que assumem contornos que vão muito além do puro registro fotográfico, tornando-se formas "não verbais e visuais de comunicação que

\section{POLÊM!CA $\mid$ LABORE}


sugerem pensamentos, intenções, emoções e desejos de alguém” (p. 1832). Nesse sentido, os autores consideram que as selfies tiradas pela população pesquisada representam um exercício de liberdade, autorreflexão e fortalecimento das conexões interpessoais:

Para eles, as selfies eram de longe muito mais do que instrumento de comunicação e auto-representação. Eles percebiam, usavam e experienciavam as selfies numa densa forma sociocultural de empoderamento: eles poderiam escapar dos olhos dos poderosos chefes do tráfico para implicitamente expressar sua insatisfação e objeções; conscientemente refletir sobre seu verdadeiro eu e manter sua pureza espiritual; superar as dificuldades de ser analfabeto funcional e gradualmente aprender habilidades de alfabetização; e melhorar a sua comunicação interpessoal com os membros da família e seus pares. (NEMER, FREEMAN, 2015, p. 1843).

Além das selfies, uma das formas de expressão utilizadas por essa parcela da população para expor seus pensamentos e sentimentos, Nemer (2015) releva que os moradoras das favelas do Brasil que foram alvo de investigação de sua pesquisa encontram nas redes sociais um lugar seguro e importante onde, além de expressar suas opiniões sobre a vida na comunidade e outros assuntos que vivenciam, podem sentir-se parte de uma sociedade dominada pelo consumo. Isso equivale a dizer que, na medida em que mostram que estão presentes no mundo virtual, usufruindo de seus aparatos e recursos, percebem-se incluídos e pertencendo à sociedade do consumo. Como bem aponta Barros (2011):

As apropriações dos segmentos populares no campo das novas tecnologias procuram, em grande parte a dissolução de esquemas hierárquicos como o falado, através do estabelecimento de relações mais igualitárias com o outro, que se fundam a partir da ideia de "ter acesso" ao "novo mundo" das conexões contemporâneas. (BARROS, 2011, p. 13).

Ademais, Nemer (2015) revela em sua pesquisa que muitos dos aparelhos celulares, chamados de "xing ling" por moradores de comunidades do Espírito Santo, eram compartilhados entre turmas de amigos que se encontravam em Telecentros e/ou lan houses para fazer uso dos aparelhos juntos. Tudo isso, cria um senso comunitário, além de estimular a sociabilidade. Castells (2013) destaca também o papel de qualificação da internet que "reforça os sentimentos de segurança, liberdade pessoal e influência - todos com efeito positivo sobre o bem-estar pessoal" (p. 174).

Dessa forma, o acesso à internet $\mathrm{e}$ às ferramentas tecnológicas passa a ser considerado como um instrumento que dá esperança e que aponta para uma porta de entrada numa sociedade menos desigual e mais democrática, tal como anunciavam Levy (1996) e Castells

\section{POLÊM!CA $\mid$ LABORE}

Polêmica - Revista Eletrônica da Uerj - Rua São Francisco Xavier, 524, $1^{\circ}$ andar

bloco D, sl.1001 • Tels.: +55 21 2334-4088/4087 • http://www.e-publicacoes.uerj.br/index.php/polemica/index

http://www.labore.uerj.br • laboreuerj@yahoo.com.br 
(1999) ao considerarem as possibilidades trazidas pelas redes virtuais de espaços enquanto mais igualitários e democráticos.

Ao analisar os exemplos descritos, percebe-se que a internet pode estar relacionada ao empoderamento, principalmente no nível individual, que pode ser descrito como a construção de um ambiente que possibilita "as pessoas sentirem que são competentes em uma determinada situação, que sua presença é relevante, têm mais oportunidades e recursos para agir que constrangimentos e limitações" (HOROCHOVSKI; MEIRELLES, 2007, p. 495).

Cabe destacar que o empoderamento pode ser entendido como um "processo pelo qual indivíduos, organizações e comunidades angariam recursos que lhes permitam ter voz, visibilidade, influência e capacidade de ação e decisão" (HOROCHOVSKI; MEIRELLES, 2007, p. 486). Ou seja, trata-se da possibilidade de que os indivíduos possam participar e ter poder de decisão naquilo que afeta suas vidas. Nesse sentido, empoderar-se pode ser entendido como a construção de um espaço de liberdade, ação voz e visibilidade. Ainda segundo Horochovski e Meirelles (2007), há diversas formas de empoderamento, que pode ocorrer individualmente ou em grupo, que passam desde ações inseridas em políticas públicas a movimentos promovidos pelos próprios cidadãos que utilizam recursos cotidianos para criar estratégias de se fazerem escutados. Parece-nos que a internet e seus recursos podem entram exatamente nesse lugar de busca por autonomia e por uma saída da inviabilidade, já que, muitas vezes, são ignorados pelas demais camadas da sociedade e pelo Estado.

Para além das intervenções individuais, há também aquelas que são idealizadas por grupos. Os "rolezinhos" são o exemplo mais recente disso. Em geral, esse tipo de evento é organizado por jovens pertencentes às classes populares, com certo reconhecimento e grande de números de seguidores nas redes socais, que convidam seus amigos para um grande encontro num lugar originalmente inacessível para eles como os shopping centers e praças públicas fora da periferia. Trata-se de um movimento que, de certa forma, empodera os jovens a ocupar espaços públicos até então considerados "exclusivos" da elite brasileira. Tais ações impulsionadas pela internet também produzem impactos no sentimento de pertencimento desses indivíduos, visto que socialmente o shopping center é considerado como o ícone da sociedade do consumo.

\section{POLÊM!CA $\mid$ LABORE}


Mesmos que esses movimentos tenham sido criminalizados pela polícia e por grande parte da sociedade brasileira, foram de extrema importância, pois viabilizaram o início da descoberta de novos espaços e modos de socialização, até então bastante limitados para as classes populares que, por sua vez, deveria ficar confinada às periferias e formas culturais apropriadas para os "pobres".

Cabe destacar que, de acordo com Castells (2013), os movimentos sociais impulsionados pelas redes sociais são desencadeados por "um processo de ação comunicativa" (p. 162) que estimula a ação e a mudança social que, por sua vez, reforçam o entusiasmo dos indivíduos que conseguem superar seu medo e "transformam-se num ator coletivo consciente" (p. 162). Dessa maneira, a função social da internet se mostra essencial na contemporaneidade no que concerne à ampliação de cenários nos quais transformações possam ser edificadas e exista a possibilidade de passagem do sentimento de indignação para a esperança. Nas palavras do autor:

\begin{abstract}
As pessoas só podem desafiar a dominação conectando-se entre si, compartilhando sua indignação, sentindo o companheirismo e construindo projetos alternativos para si próprias e para a sociedade como um todo. Sua conectividade depende de redes de comunicação interativas. Em nossa sociedade, a forma fundamental de comunicação horizontal em grande escala baseia-se na internet e redes sem fio. (CASTELLS, 2013, p. 17).
\end{abstract}

\title{
Considerações finais
}

Ainda que haja resistência da elite em aceitar que as classes menos favorecidas economicamente usufruam do mesmo espaço virtual, como o Facebook, Instagram e Snapchat, chegando inclusive a migrar para outras redes em momentos que consideram seu terreno invadido, a população de baixa renda continua lutando pela construção de um lugar onde possam se expressar e interagir livremente longe do preconceito e repressão provenientes de diversos atores sociais.

Barros (2011) cita em seu trabalho diversos exemplos de comentários discriminatórios e excludentes no Orkut por parte da elite que criou definições e padrões de consumo e comportamento que passaram a associar à pobreza. Assim, tudo que era definido como "pobre" deveria ser banido de seu espaço que seria exclusivo para aqueles que se encaixavam em seus parâmetros. Gostaríamos de chamar a atenção para a resistência de alguns membros das classes populares que se recusaram a sair dessa rede social e se esforçaram para manter

\section{POLÊM!CA $\mid$ LABORE}


seu espaço, através de posts que reforçam sua cultura e modo de ser. Informação corroborada por Nemer (2015) que ressalta os comentários das classes médias e alta sobre o mau uso do português, as fotos consideradas de mau gosto e a falta de educação dos "pobres" que na opinião dessa parcela da população estariam deteriorando o Orkut.

Sentindo que estavam sendo discriminados e excluídos de alguns grupos do Orkut, grande parte dos indivíduos das classes populares migrou para o Facebook, rede social onde de fato passaram a se sentir à vontade para postar suas opiniões, ainda que tenham havido sinais de que algo parecido com o que ocorreu no Orkut fosse acontecer na nova rede, já que a elite também havia migrado para ela.

Assim, ao se sentirem como parte da comunidade virtual de forma mais igualitária, ainda que tenham certo receio de serem julgados, começam a construir formas particulares de fazer uso dos recursos do Facebook, seja para conversar com um familiar do qual estão distantes, para expressar sua individualidade, para manter contato com os pais - que trabalham, muitas vezes, em vários empregos - atualizando-os de sua localização, seja também para manifestar a sua indignação com a situação em que vivem ou emitir opiniões sobre os assuntos de sua vida e comunidade (NEMER, 2015).

Além do Facebook, o Youtube também tem sido bastante utilizado como uma forma de entretenimento e descanso, além da perspectiva de encontrar novos horizontes, novas esperanças, como aprender alguma atividade que possa gerar renda ou descobrir novos interesses que até então estavam restritos a determinada parcela da população.

Para além do entretenimento, o Facebook tem sido uma potente estratégia de divulgação e combate ao preconceito e um instrumento facilitador de expressão de diferentes anseios. Dois bons exemplos de páginas podem ser citados: o coletivo Nuvem Negra, surgido na Pontifícia Universidade Católica (PUC-Rio), e os Bastardos da PUC.

$\mathrm{Na}$ página do primeiro podemos ler: "Somos estudantes negras/os da PUC-Rio. Compartilhamos da resistência, do afeto, da afirmação da identidade negra e, sobretudo, do combate ao racismo" (COLETIVO NUVEM NEGRA, 2017).

Os Bastardos da PUC, cuja página traz relatos de discriminações vividas, utilizam-se também da página para conscientização e reivindicação dos direitos.

Amanhecemos com um direito a menos. Hoje (20), nós bolsista/cotistas/estudantes de baixa renda recebemos a notícia de que não temos mais o direito ao passe livre universitário durante o recesso. Só nós sabemos quanto o passe livre universitário é

\section{POLÊM!CA $\mid$ LABORE}


essencial para nossa locomoção pela cidade, pois entendemos que a graduação vai além de uma aula expositiva numa sala de aula e temos o direito de ir e vir à espaços que nutrem nosso conhecimento que tanto nos auxiliam na nossa formação acadêmica e social. Hoje é a perda do passe livre durante as férias, amanhã será nos finais de semana e feriados? E depois perderemos de vez nossos direitos? Frente a isso, convocamos todos os alunos da PUC-Rio, em especial aos contemplados pelo direito ao passe livre universitário, para somar no Ato contra o bloqueio dos nossos direitos, segunda-feira (23) às $17 \mathrm{~h}$, contra a perda do nosso direito. Vamos juntos!! \#NenhumDireitoAMenos (ATO CONTRA O BLOQUEIO DOS NOSSOS DIREITOS, 2017).

Como bem apontam Carvalho e Vasconcelos (2012), com base em uma pesquisa com seguidores, moradores das periferias de diversas regiões do Brasil, do site "Viva Favela" (que foi idealizado com base na concepção colaborativa) e do blog "Mamíferas", "a partir de uma comunicação horizontal, integrantes dos chamados grupos minoritários tem a oportunidade de expressar as ideias, além de encontrar os pares e compartilhá-las com os mesmos” (p. 1).

Postar uma selfie, um vídeo, uma letra, uma palavra é, portanto, uma tentativa de sair da invisibilidade e de ter sua cultura reconhecida. Não é raro vermos vídeos de jovens que divulgam suas letras de rap, suas danças, músicas e poesias. Mais do que uma aparição narcísica, é notável o desejo de que sua cultura seja reconhecida e valorizada e que novas portas para outros lugares sejam abertas, como nos exemplos das páginas criadas por dois coletivos no Facebook.

Nesse sentido, ainda que sejam necessárias mais investigações sobre o tema, concluise que a internet abre novas possibilidades para que os sujeitos das classes populares sintamse mais capacitados para mudar a própria realidade, ou seja, empoderem-se e sintam-se capazes de tomar decisões mais autônomas, por meio das quais terão suas vozes escutadas, seja por um texto, vídeo, imagem ou fotografia.

\section{Referências}

ARAÚJO, Y. R. G. Telepresença: interação e interfaces. São Paulo: EDUC/Fapesp, 2005.

ATO CONTRA O BLOQUEIO DOS NOSSOS DIREITOS. [Comentário pessoal]. Facebook. 19 de janeiro de 2017. Disponível em: <https://www.facebook.com/events/1842478592690419> Acesso em: 18 jan. 2017.

BARROS, C. F. P. "Pobreza" e tecnologia no olhar do outro: representações sobre diferenças culturais. Anais do XX Encontro da Compós, 2011, p. 1-17.

CARVALHO, C. S.; VASCONCELOS, Eulália Teixeira de. O Empoderamento das "minorias" por meio das mídias sociais: a conexão dos pares no site Viva Favela e no blog Mamíferas. Anais do XXXV Congresso Brasileiro de Ciências da Comunicação, 2012, p. 1-15.

\section{POLÊM!CA $\mid$ LABORE}


CASTELLS, M. Redes de indignação e esperança. Rio de Janeiro: Zahar, 2013.

Mobile communication and society: A global perspective. Cambridge, MA: MIT Press, 2006.

A sociedade em rede. São Paulo: Paz e Terra, 1999.

CENTRO REGIONAL DE ESTUDOS PARA O DESENVOLVIMENTO DA SOCIEDADE DA INFORMAÇÃO (CETIC). Tecnologia de Informação e Comunicação Domicílios - TIC Domicílios Brasil, 2015.

COLETIVO NUVEM NEGRA. [Comentário pessoal]. Facebook. 10 de janeiro de 2017. Disponível em: $<$ https://www.facebook.com/coletivonuvemnegra > Acesso em: 11 jan. 2017.

DIAS, A.C.G.; DE LA TAILLE, Y. As salas de bate papo na Internet são um novo espaço para o compartilhamento da intimidade? In: MALUF, Maria Regina. Psicologia educacional: questões contemporâneas. São Paulo: Casa do Psicólogo, 2004. p. 187-219.

HOROCHOVSKI, R.R.; MEIRELLES, Giselle. Problematizando o conceito de empoderamento. Anais do II Seminário Nacional: Movimentos sociais, participação e democracia, 2007, p. 485- 506.

LEVY, P. O que é o virtual ?. São Paulo: Editora 34, 1996.

Cibercultura. Editora 34: São Paulo. 1999. Disponível em: <https://mundonativodigital.files.wordpress.com/2016/03/cibercultura-pierre-levy.pdf>. Acesso em: 05 jan. 2017.

NEMER, D. Online favela: the use of social media by the marginalized in Brasil. Information Technology for Development, 2015, p. 1-26.

NEMER, D.; FREEMAN, G. Empowering the Marginalized: Rethinking Selfies in the Slums of Brazil. International Journal of Communication, v.9, p. 1832-1847, 2015.

Recebido em: 29/01/2017.

Aceito em: 30/03/2017.

\section{POLÊM!CA $\mid$ LABORE}

